Section Editor

Mitchell S.V. Elkind,

MD, MS

Bhawana Kumari, MD

Manoj K. Goyal, DM

Vivek Lal, DM

Correspondence to

Dr. Lal:

vivek144@yahoo.com

Pearls \& Oy-sters:

\title{
Bilateral cavernous sinus syndrome as presenting manifestation of nasopharyngeal carcinoma
}

PEARLS

- Nasopharyngeal carcinoma commonly presents with trismus, pain, otitis media, nasal regurgitation (due to paresis of the soft palate), hearing loss, and cranial nerve palsies. ${ }^{1}$ Incidence of cranial nerve involvement varies from $12 \%$ to $35 \%$. $^{2}$

- In order of prevalence, the most commonly affected cranial nerves include the trigeminal, abducens, oculomotor, and hypoglossal. ${ }^{2}$

\section{OY-STER}

- Cranial nerve palsy at initial presentation is observed in $12 \%-35 \%$ of patients, but it is not clear what percentage of patients present only with cranial nerve involvement.

CASE REPORT A 48-year-old man presented to our hospital with an acute-onset, severe, persistent holocranial headache of 3 months' duration. $\mathrm{He}$ also noted binocular horizontal diplopia, drooping of the left eyelid, and inward deviation of the left eye that began at the same time as the headache. The symptoms worsened gradually and within a few weeks he developed drooping of the right eyelid as well. He also complained of gradually progressive hearing loss with tinnitus, beginning in the left ear and progressing to the right ear. There were no other systemic or neurologic symptoms. There was no history of smoking or drug/alcohol abuse. He was a security guard by profession. General physical examination revealed a firm $1 \times 1 \mathrm{~cm}$ painless cervical lymph node. Ophthalmologic examination revealed bilateral sixth, bilateral partial third, and right fourth cranial nerves palsy (figure 1). Fundus examination did not reveal any abnormality. Bilateral conductive hearing loss was also present. The remainder of the neurologic examination was normal. He was diagnosed with bilateral cavernous sinus syndrome and bilateral sequential conductive deafness. The etiologic possibilities considered at this stage included noninfectious granulomatous conditions (such as sarcoidosis and Tolosa-Hunt syndrome), infectious etiologies (fungal, tuberculosis, or other chronic infection), or malignancies (a primary sellar mass with parasellar extension, an extrasellar mass with bilateral extension into parasellar space, or metastasis). His hematologic profile, blood glucose, renal and liver function tests, serum angiotensinconverting enzyme levels, and CSF examination results were within normal limits. HIV serology was negative. He underwent a noncontrast CT scan of the head (figure 2), which revealed an ill-defined mildly hyperattenuating mass causing destruction of the sphenoid bone including the sella and clivus. The mass extended to the parasellar region, sphenoid sinuses, and prepontine region bilaterally. On MRI (figure 2), a large mass was seen involving the posterosuperior aspect of the nasopharynx, as well as the sphenoid bone with destruction of the sella and clivus, sparing the basilar artery. The mass encased both internal carotid arteries without any luminal compromise. It appeared isointense with central hypointensity on T1-weighted imaging and hyperintense on T2-weighted images with heterogeneous postcontrast enhancement.

Histopathologic examination of the mass was consistent with an undifferentiated squamous cell nasopharyngeal carcinoma (NPC) (figure 3). Radiotherapy with a midplane dose of $30 \mathrm{~Gy}$ in 15 fractions weekly was started, and chemotherapy was planned. Since initiating therapy, the patient has noted some improvement in the double vision and ptosis. His headache persists, though the intensity decreased significantly.

DISCUSSION NPC is a tumor arising from the epithelial cells that line the nasopharynx. NPC was first described as a separate entity by Regaud ${ }^{3}$ in 1921 . Currently, 3 subtypes of NPC are recognized in the World Health Organization classification ${ }^{4}$ : type 1, squamous cell carcinoma, typically found in the older adult population; type 2 , nonkeratinizing carcinoma; and type 3, undifferentiated carcinoma. Most cases seen in childhood and adolescence are of the undifferentiated type, and approximately one-third of all undifferentiated NPCs are diagnosed in adolescents or young adults. ${ }^{1}$ The annual incidence of NPC varies by geographic region. ${ }^{1,5}$ Incidence is high in Tunisia

From the Department of Neurology, Post Graduate Institute of Medical Education and Research Centre, Chandigarh, India.

Go to Neurology.org for full disclosures. Funding information and disclosures deemed relevant by the authors, if any, are provided at the end of the article. 


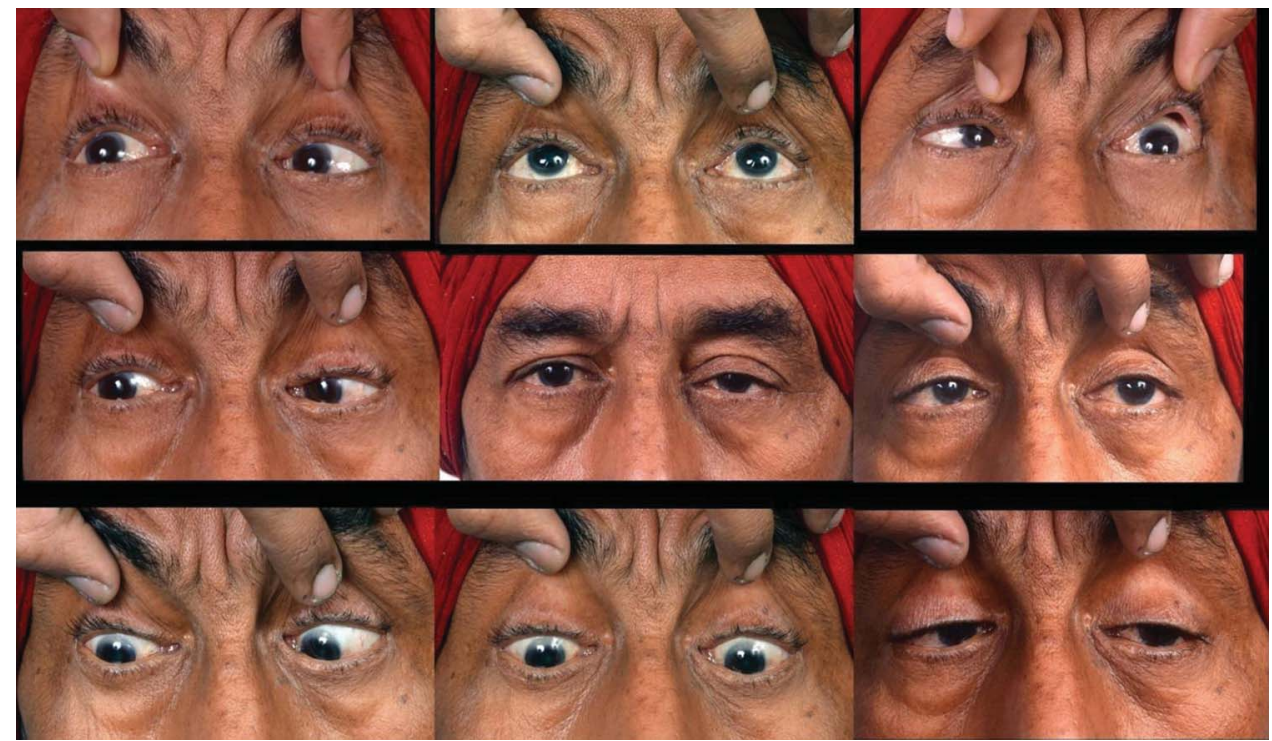

Ophthalmologic examination shows bilateral partial third and sixth cranial nerves palsy.

and moderately high in Southeast Asia, China, the Mediterranean basin, and Alaska. It is low in the United Kingdom and India (0.9 per million). The Epstein-Barr virus, ethnic background of the patient,

\section{Figure 2 CT and MRI demonstrate findings consistent with nasopharyngeal carcinoma}

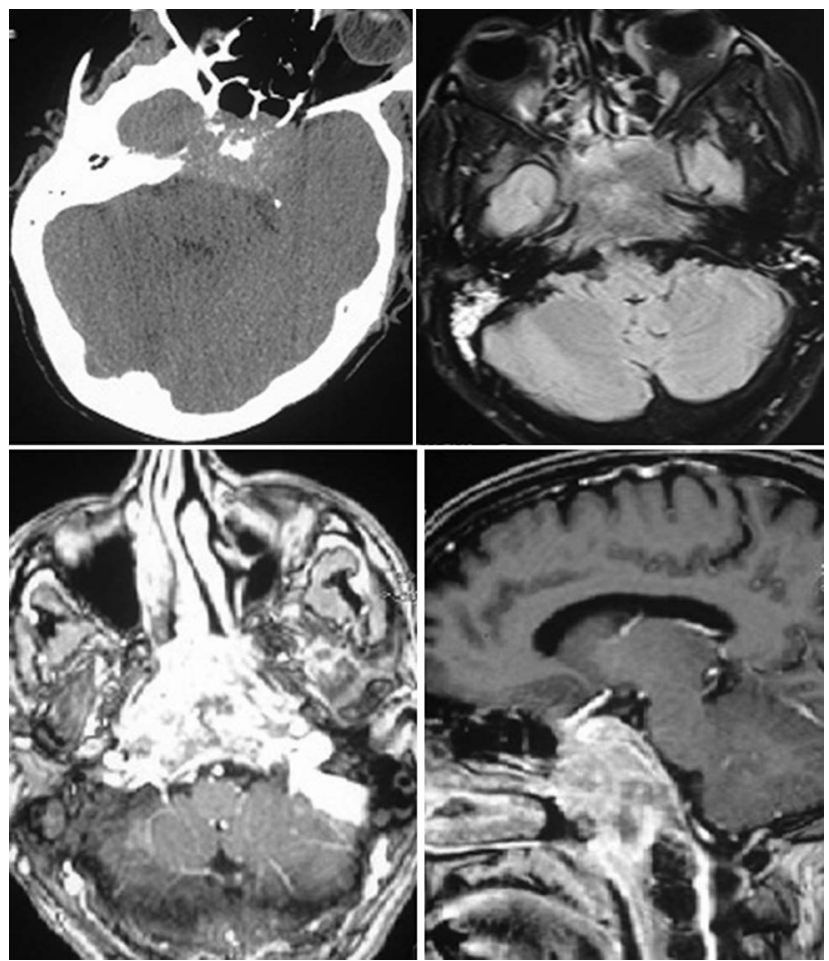

CT head shows an ill-defined mildly hyperattenuating mass causing destruction of sphenoid bone including the sella and clivus. T2 fluid-attenuated inversion recovery images show a mass involving the sphenoid bone with destruction of the sella and clivus with further extension to neighboring structures. Postcontrast T1-weighted images show heterogeneous contrast enhancing nasopharyngeal mass with longitudinal extension. and environmental carcinogens (volatile nitrosamines) all seem to play an important role in the pathogenesis of NPC. 5

NPC usually originates in the lateral wall of the nasopharynx in the nasopharyngeal recess. It can then extend within or out of the nasopharynx to the contralateral wall or posterosuperiorly to the base of the skull or the palate, nasal cavity, or oropharynx. ${ }^{1}$ It then can metastasize to cervical lymph nodes. Distant metastases may occur in bone, lung, mediastinum, and rarely in liver. Cervical lymphadenopathy is a common initial presentation and in many patients the diagnosis is made by lymph node biopsy. Symptoms related to the primary tumor include trismus, pain, otitis media, nasal regurgitation, hearing loss, and cranial nerve palsies. Larger growths may produce nasal obstruction or bleeding and a "nasal twang."

Most of these neoplasms infiltrate aggressively. They grow within the nasopharynx or can spread anteriorly, laterally, posteriorly, superiorly, and inferiorly to the contralateral wall. NPC can also infiltrate other structures toward the base of the skull and invade the palate, nasal cavity, or the oropharynx. NPC can spread intracranially via the foramen lacerum or foramen ovale or through both foramina. It can also spread by direct erosion, which results in multiple cranial deficits. Perineural infiltration through the foramen ovale is an important route of spread resulting in invasion of the cavernous sinuses as was seen in our patient. Cranial nerve palsies, if present, are associated with a worse prognosis as compared to invasion of the base of the skull. ${ }^{6}$ Patients with cranial nerve palsies may need more aggressive treatment. A favorable response to definitive radiation 


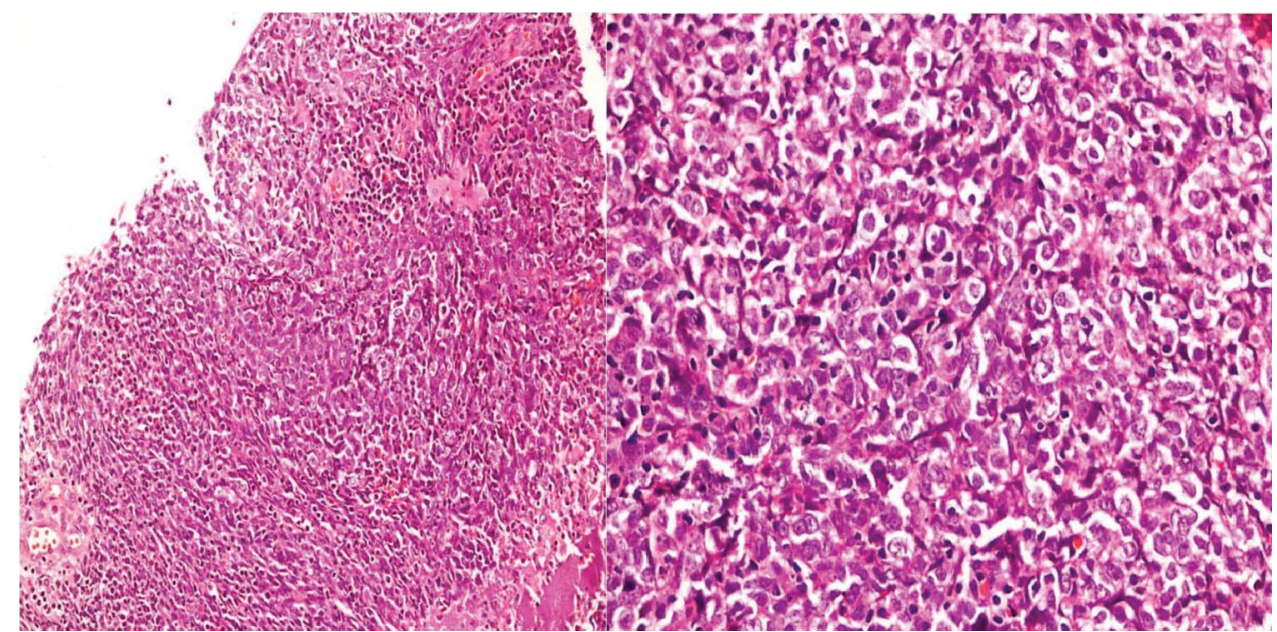

Histopathologic examination reveals tumor cells arranged in sheets and nests with features suggestive of undifferentiated nasopharyngeal carcinoma.

therapy has been documented in such patients. Local growth of the tumor can involve the Eustachian tube (by direct involvement, invasion of the tensor palatini muscle, or because of tube displacement) leading to middle ear effusion and hearing disturbances. ${ }^{15,7-9}$

Ophthalmo-neurologic manifestations are common at time of first presentation in patients with NPC. In a series of 124 patients, signs of cranial nerve involvement were seen in $48(38.7 \%)$ patients at presentation. ${ }^{2}$ The most commonly affected cranial nerves were the abducens in $11(22.9 \%)$, trigeminal in 10 (20.8\%), oculomotor in $6(12.5 \%)$, and hypoglossal in $5(10.4 \%)$. However, multiple cranial nerve dysfunction was seen in only $3 / 124(2.4 \%)$ patients. This suggests that though cranial nerve involvement is common, finding multiple cranial nerve palsies is relatively rare at presentation in NPC. With regards to cavernous sinus syndrome, Agrawal et al. ${ }^{7}$ reported unilateral cavernous sinus syndrome as a presenting manifestation of NPC. However, bilateral cavernous sinus syndrome as a presenting manifestation of NPC, as seen in our patient, has not been reported in literature to our knowledge. This case expands the spectrum of neurologic findings as the presenting manifestation of NPC.

This case illustrates the difficulty of diagnosing NPC in the early stages for various reasons, including nonspecificity of initial symptoms and problems associated with the examination of the postnasal space. However, careful examination of the nasopharynx often reveals the lesion. CT scan supplemented with MRI is currently the investigation of choice for accurate tumor mapping and detection of possible tumor extension, especially for the skull base and the deep facial spaces. In the present case, MRI also revealed cavernous sinus involvement and extension in and around the nasopharynx. The CT scan revealed the extent of bony erosion.
Our case further expands the clinical spectrum of this tumor and illustrates the importance of keeping a high index of suspicion for NPC in patients presenting with cavernous sinus syndrome. In this regard, it is important to emphasize that though NPC is commonly not amenable to surgery by virtue of its location, it is an exquisitely radiosensitive tumor. ${ }^{10}$

\section{AUTHOR CONTRIBUTIONS}

Bhawana Kumari: acquisition of data, data analysis and interpretation. Manoj Goyal: critical revision of the manuscript for important intellectual content. Vivek Lal: study concept and design, study supervision.

\section{STUDY FUNDING}

No targeted funding reported.

\section{DISCLOSURE}

The authors report no disclosures relevant to the manuscript. Go to Neurology.org for full disclosures.

\section{REFERENCES}

1. Brennan B. Nasopharyngeal carcinoma. Orphanet J Rare Dis 2006;1:23.

2. Turgut M, Erkurt O, Saygi S, Ozcan OE. Importance of cranial nerve involvement in nasopharyngeal carcinoma: a clinical study comprising 124 cases with special reference to clinical presentation and prognosis. Neurosurg Rev 1998;21:243-248.

3. Regaud C. Lympho-épitheliome de l'hypopharynx traité par la roentgenthérapie. Bull Soc Franc Otorhinolaryngol 1921;34:209-214.

4. Shanmugaratnam KS, Sobin LH. Histological Typing of Upper Respiratory Tract Tumors. Geneva: World Health Organization; 1978.

5. Chang ET, Adami HO. The enigmatic epidemiology of nasopharyngeal carcinoma. Cancer Epidemiol Biomarkers Prev 2006;15:1765-1777.

6. Sham JST, Choy D. Prognostic factors of nasopharyngeal carcinoma: a review of 759 patients. Br J Radiol 1990;63:51-58. 
7. Agrawal A, Baisakhiya N, Vagh SJ, Joharapurkar SR Nasopharyngeal carcinoma presenting with cavernous sinus involvement, trigeminal neuralgia and middle ear effusion. Int J Clin Pract 2009;4:203-207.

8. Dubrulle F, Souillard R, Hermans R. Extension patterns of nasopharyngeal carcinoma. Eur Radiol 2007;17: 2622-2630.
9. Wei WI, Sham JS. Nasopharyngeal carcinoma. Lancet 2005; 365:2041-2054.

10. Cooper JS, Lee H, Torrey M, Hochster H. Improved outcome secondary to concurrent chemoradiotherapy for advanced carcinoma of the nasopharynx: preliminary corroboration of the intergroup experience. Int J Radiat Oncol Biol Phys 2000;47:861-866. 


\section{Neurology}

\section{Pearls \& Oy-sters: Bilateral cavernous sinus syndrome as presenting manifestation of nasopharyngeal carcinoma}

Bhawana Kumari, Manoj K. Goyal and Vivek Lal

Neurology 2014;82;e51-e54

DOI 10.1212/WNL.0000000000000103

\section{This information is current as of February 10, 2014}

\section{Updated Information \&} Services

References

Subspecialty Collections

\section{Permissions \& Licensing}

Reprints including high resolution figures, can be found at: http://n.neurology.org/content/82/6/e51.full

This article cites 9 articles, 2 of which you can access for free at: http://n.neurology.org/content/82/6/e51.full\#ref-list-1

This article, along with others on similar topics, appears in the following collection(s):

All Neuro-ophthalmology

http://n.neurology.org/cgi/collection/all_neuroophthalmology Audition

http://n.neurology.org/cgi/collection/audition

CT

http://n.neurology.org/cgi/collection/ct

\section{MRI}

http://n.neurology.org/cgi/collection/mri

Primary brain tumor

http://n.neurology.org/cgi/collection/primary_brain_tumor

Information about reproducing this article in parts (figures,tables) or in its entirety can be found online at:

http://www.neurology.org/about/about_the_journal\#permissions

Information about ordering reprints can be found online: http://n.neurology.org/subscribers/advertise

Neurology ${ }^{\circledR}$ is the official journal of the American Academy of Neurology. Published continuously since 1951, it is now a weekly with 48 issues per year. Copyright @ 2014 American Academy of Neurology. All rights reserved. Print ISSN: 0028-3878. Online ISSN: 1526-632X.

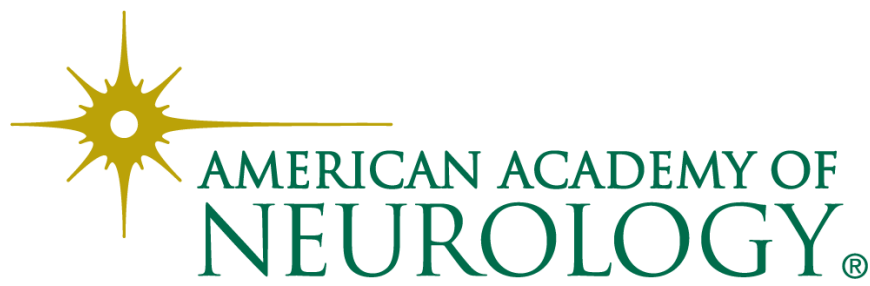

